\title{
Erratum to: Ecological Factors of Being Bullied Among Adolescents: a Classification and Regression Tree Approach
}

\author{
Sung Seek Moon ${ }^{1}$ • Heeyoung Kim ${ }^{2}$ - Kristen Seay ${ }^{1}$. \\ Eusebius Small $^{3}$ - Youn Kyoung Kim ${ }^{3}$
}

Published online: 21 November 2015

(C) Springer Science+Business Media Dordrecht 2015

\section{Erratum to: Child Ind Res \\ DOI 10.1007/s12187-015-9343-1}

The original article contained an error.

The name of the third author should have been Kristen Seay not Seay Kristen.

The corrected author name is shown above.

The online version of the original article can be found at doi:10.1007/s12187-015-9343-1.

\section{Sung Seek Moon}

sungseek@mailbox.sc.edu

1 College of Social Work, University of South Carolina, Columbia, SC 29208, USA

2 Department of Child Welfare, Namseoul University, Cheonan, South Korea

3 School of Social Work, University of Texas at Arlington, Arlington, TX, USA 